\title{
Infantile Scimitar Syndrome With Contralateral Pulmonary Vein Stenosis and Refractory Pulmonary Hypertension
}

\author{
Janelle Buysse ${ }^{1}$, Ramya Deepthi Billa ${ }^{2}$, Daniel McLennan ${ }^{1}$, Ravi Ashwath ${ }^{1}$, Aditya Badheka ${ }^{3,4}$, \\ Madhuradhar Chegondi 4 \\ 1. Pediatric Cardiology, University of Iowa Stead Family Children's Hospital, Iowa City, USA 2. Division of Critical Care \\ Medicine, University of Iowa Stead Family Children's Hospital, Iowa City, USA 3. Pediatrics, University of Iowa \\ Hospitals and Clinics, Iowa City, USA 4. Pediatrics, University of Iowa Stead Family Children's Hospital, Iowa City, USA
}

Corresponding author: Janelle Buysse, janelle-buysse@uiowa.edu

\section{Abstract}

Infantile scimitar syndrome is associated with pulmonary hypertension which can be difficult to manage. We present a three-month-old infant with scimitar syndrome, who eventually developed refractory pulmonary hypertension, posing a significant management challenge. Further workup demonstrated contralateral pulmonary vein stenosis, which is rarely described in scimitar syndrome. Our index case highlights the importance of follow-up cardiac catheterizations in these patients with severe pulmonary hypertension.

Categories: Cardiology, Pediatrics

Keywords: scimitar syndrome, pulmonary vein stenosis, pulmonary hypertension, infantile scimitar syndrome, cardiac catheterization

\section{Introduction}

This article was previously presented as a meeting abstract at the Society for Critical Care Medicine Annual Conference in February 2021.

Scimitar syndrome is a rare congenital cardiac defect characterized by anomalous pulmonary venous drainage from the right lung to the inferior vena cava [1]. The infantile form of scimitar syndrome presents with severe symptoms, including pulmonary hypertension, and has a high risk of mortality compared to the adult type [1]. Though scimitar vein obstruction is common in these patients, contralateral pulmonary vein stenosis (PVS) is rarely described [2].

\section{Case Presentation}

\section{History of presentation}

Review began 06/17/2021 Review ended 08/11/2021 Published 08/15/2021

๑) Copyright 2021

Buysse et al. This is an open access article distributed under the terms of the Creative Commons Attribution License CC-BY 4.0., which permits unrestricted use, distribution, and reproduction in any medium, provided the original author and source are credited.
A three-month-old female with a history of scimitar syndrome presented to the emergency department for evaluation of increased work of breathing. In the emergency department, she was started on oxygen via nasal cannula and transferred to our pediatric cardiac intensive care unit (PCICU). On arrival to our PCICU, her oxygen saturation was $85 \%$ with tachypnea, intercostal retractions and clear breath sounds on auscultation. Her respiratory support was escalated to high-flow nasal cannula (HFNC).

\section{Past medical history}

She had been diagnosed with scimitar syndrome during workup for tachypnea and persistent oxygen desaturation. She was found to have stenosis of the scimitar vein and underwent balloon angioplasty. Following the procedure, she recovered quickly and was discharged home.

\section{Investigations}

Chest X-ray demonstrated right pulmonary hypoplasia with dextroposition and scoliosis (Figure 1). 


\section{Cureus}

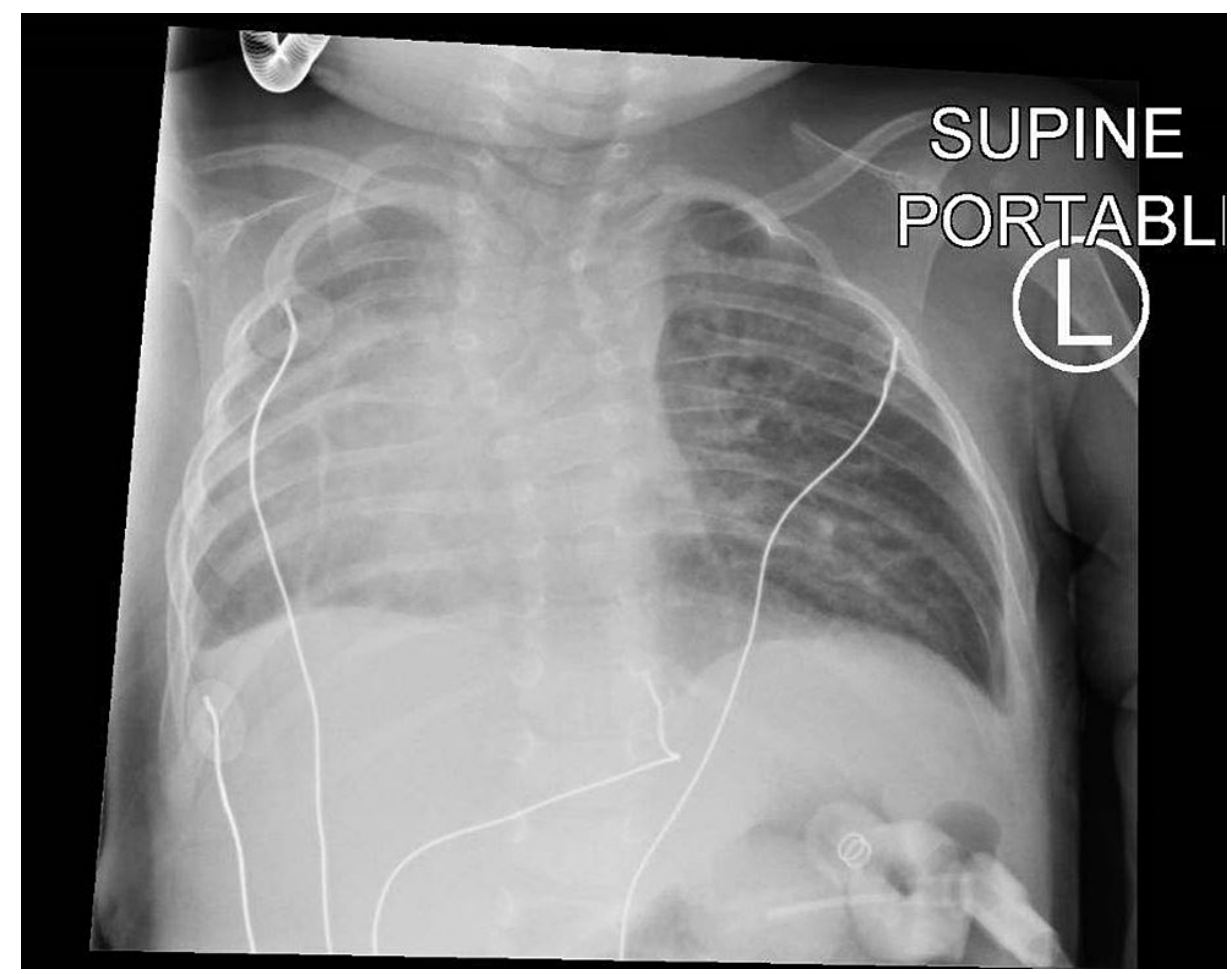

FIGURE 1: Initial chest X-ray demonstrating right pulmonary hypoplasia, dextroposition, and scoliosis

A transthoracic echocardiogram (TTE) revealed dextroversion with partial anomalous venous return drainage of all the right pulmonary veins to the infra-diaphragmatic right hepatic vein. There was a mean gradient of $12 \mathrm{mmHg}$ across the entrance of this vein. There was an atrial septal defect (ASD) with bidirectional shunt. The right ventricle was dilated with normal systolic function with flat interventricular septum during systole, indicating at least half systemic right ventricular pressure. Computed tomography angiography (CTA) revealed a scimitar vein draining into the right hepatic vein with an area of severe stenosis measuring $1.1 \mathrm{~mm}$ (Figure 2). 


\section{Cureus}

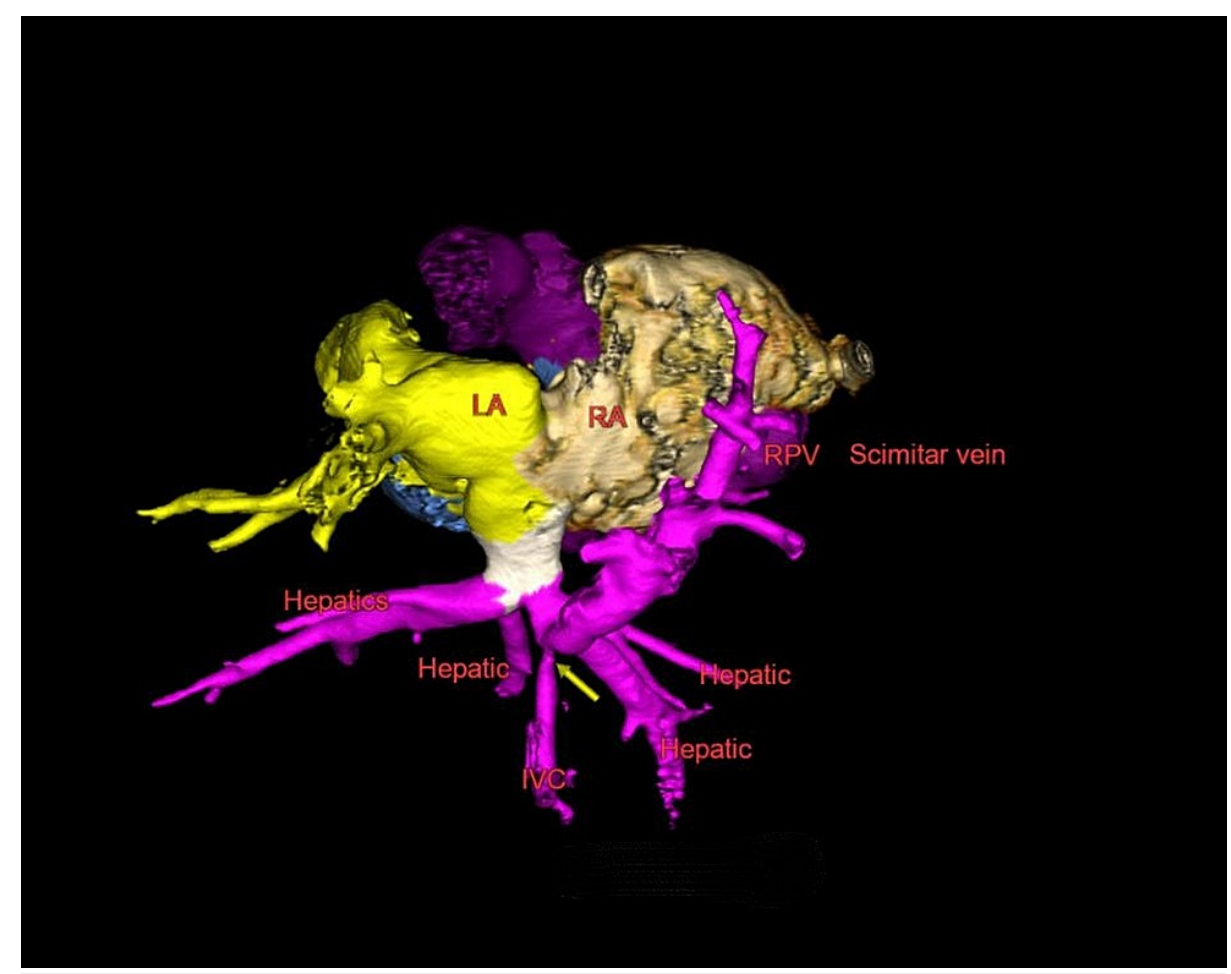

FIGURE 2: 3D reconstruction of CTA images of scimitar vein and IVC demonstrating stenosis of scimitar vein at junction with right hepatic vein

CTA = computed tomography angiogram, IVC = inferior vena cava, LA = left atrium, RA = right atrium, RPV = right pulmonary vein; Yellow arrow indicates area of stenosis.

There was a moderate-sized aortopulmonary collateral (APC) supplying the right lung (Figure 3). 


\section{Cureus}

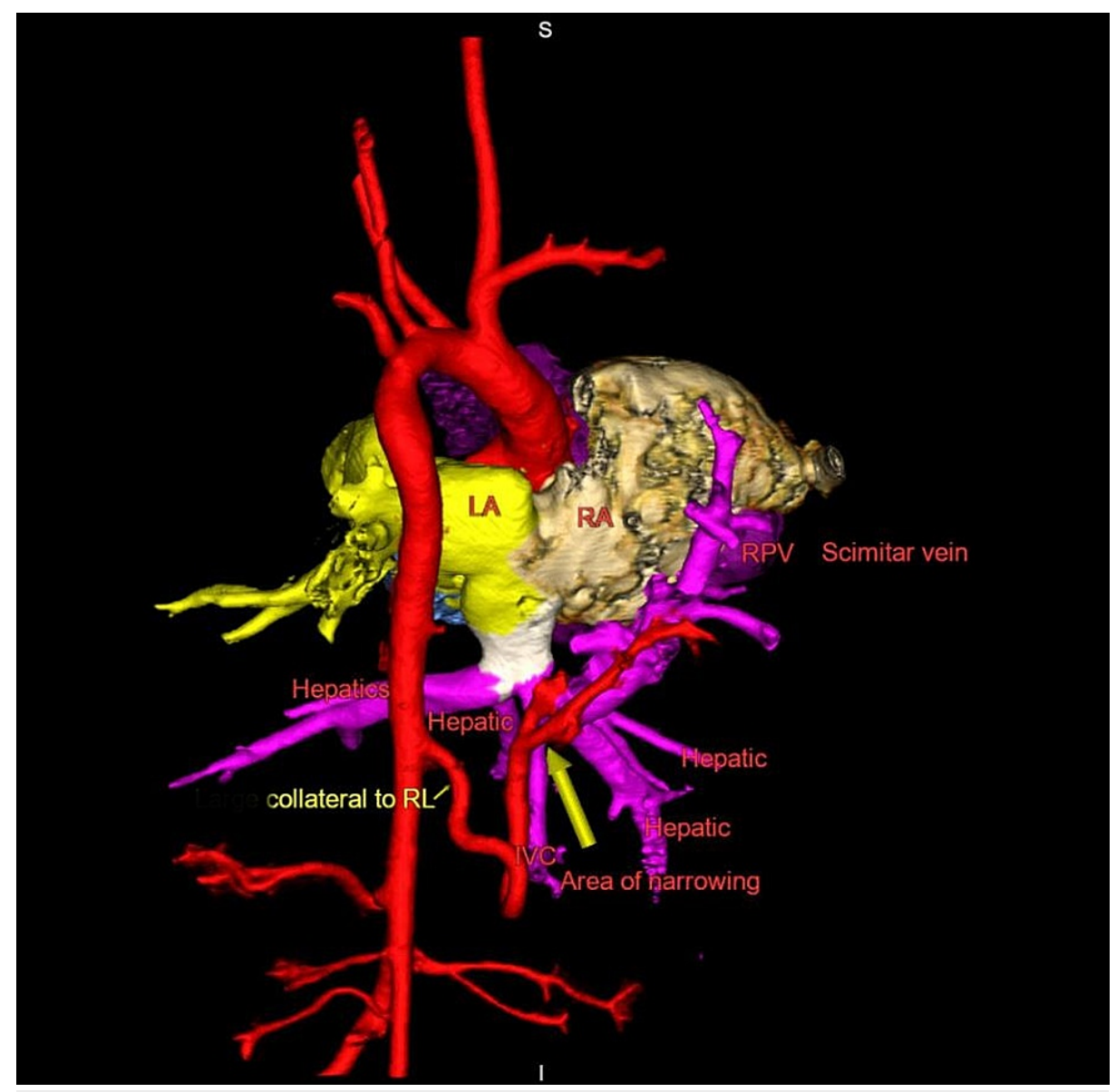

FIGURE 3: 3D reconstruction of CTA images of scimitar vein, IVC, and aorta demonstrating stenosis of scimitar vein at junction with right hepatic vein and moderate-sized aortopulmonary collateral arising from descending aorta and supplying right lower lobe

CTA = computed tomography angiogram, IVC = inferior vena cava, $\mathrm{LA}=$ left atrium, RA = right atrium, RPV = right pulmonary vein, $\mathrm{RL}=$ right lung.

The left upper and lower pulmonary veins came together into a confluence before draining, unobstructed, into the left atrium with no areas of stenosis seen.

She underwent cardiac catheterization on $60 \%$ oxygen, which revealed supra-systemic pulmonary hypertension resulting in net right to left shunt via ASD with significantly elevated indexed pulmonary vascular resistance (PVRi) at 14 WU. $\mathrm{m}^{2}$ (normal $<3$ WU. $\mathrm{m}^{2}$ ) and pulmonary to systemic blood flow ratio (Qp:Qs) of 0.8:1 (normal 1:1). With escalation to 100\% oxygen and the addition of $40 \mathrm{ppm}$ of inhaled nitric oxide (iNO), the pulmonary artery systolic pressure decreased to $80 \%$ of systemic, PVRi decreased to 3.7 WU. ${ }^{2}$, and Qp:Qs increased to 1.3:1. The scimitar vein was stented at the junction with the right hepatic vein, decreasing the gradient across that region from $11 \mathrm{mmHg}$ to $4 \mathrm{mmHg}$. A moderate APC arising from the descending aorta supplying the anterior basal segment of right lower lobe was occluded, prior to release of the vascular plug the patient was monitored for several minutes for any decrease in saturations and with the vascular plug in place iNO and fraction of inspired oxygen (FiO2) were both weaned with maintenance of saturations. The left pulmonary artery and pulmonary veins were not evaluated during this study.

\section{Management}

She returned to the PCICU, endotracheally intubated and on a mechanical ventilator. She was started on iNO and sildenafil and extubated to HFNC. She initially tolerated weaning off iNO and remained extubated, however, one week after catheterization she developed episodes of desaturation and bradycardia. During one of these episodes, she required re-intubation and the addition of intravenous epoprostenol. She continued to have frequent pulmonary hypertensive crises, 4-6 times per day, requiring escalation of sedation, initiation of paralytic infusion, addition of epinephrine, milrinone infusions, digoxin, and bosentan. 
other required tracheostomy and ventilator dependent [2-8]. Most of the reports did not include information on whether the stenotic segment was distal or proximal, however, the cases described by Argueta-Morales et al. and Onalan et al. included a description of the location of the stenosis and in both cases described the stenosis was located proximally [7,8]. Our case is the only reported case of contralateral pulmonary vein stenosis involving the proximal portion.

Pulmonary hypertension is common in infantile scimitar syndrome reported in half to two-thirds of these patients $[2,7]$. Causes of pulmonary hypertension are multifactorial, primarily due to obstruction of the scimitar or pulmonary veins and muscularization of the pulmonary arterioles in response to excess pulmonary blood flow due to left to right shunt. There are multiple sources of excess pulmonary blood flow in patients with infantile scimitar syndrome, including flow through scimitar vein, presence of APCs, and associated intracardiac shunts [2]. The presence of left to right shunt poses an additional challenge to managing pulmonary hypertension in these infants. Excessive pulmonary vasodilation can increase left to right shunting, increasing excess pulmonary blood flow and worsening the process of muscularization of the pulmonary arterioles [9].

Follow-up catheterization for pediatric patients with pulmonary hypertension is recommended in the setting of clinical worsening 3-12 months after a significant change in therapy [9]. While catheterization was frequently discussed in our patient, the risks of transportation to the catheterization lab in the setting of frequent pulmonary hypertensive crises with hemodynamic compromise were felt to outweigh the potential diagnostic and prognostic benefits. With the escalation of pulmonary vasodilators, sedation, and paralysis, she eventually had a 48-hour period free from acute episodes of instability and was able to be safely transported to the catheterization lab. Despite repeating catheterization within the recommended timeframe [9], contralateral PVS had developed, explaining the refractory nature of her pulmonary hypertension.

\section{Conclusions}

Contralateral PVS has been rarely reported in association with infantile scimitar syndrome. Our case highlights the importance of follow-up imaging particularly comprehensive diagnostic catheterization in patients with severe pulmonary hypertension. Development of contralateral PVS should be considered in scimitar syndrome patients with refractory pulmonary hypertension.

\section{Additional Information \\ Disclosures}

Human subjects: Consent was obtained or waived by all participants in this study. Conflicts of interest: In compliance with the ICMJE uniform disclosure form, all authors declare the following: Payment/services info: All authors have declared that no financial support was received from any organization for the submitted work. Financial relationships: All authors have declared that they have no financial relationships at present or within the previous three years with any organizations that might have an interest in the submitted work. Other relationships: All authors have declared that there are no other relationships or activities that could appear to have influenced the submitted work.

\section{References}

1. Vida VL, Padalino MA, Boccuzzo G, et al.: Scimitar syndrome: a European Congenital Heart Surgeons Association (ECHSA) multicentric study. Circulation. 2010, 122:1159-1166. 10.1161/CIRCULATIONAHA.109.926204

2. Huddleston CB, Exil V, Canter CE, Mendeloff EN: Scimitar syndrome presenting in infancy. Ann Thorac Surg. 1999, 67:154-159. 10.1016/S0003-4975(98)01227-2

3. Di Filippo S: Chapter 5 - Epidemiology and physiopathology of scimitar syndrome . In: The Complete Reference for Scimitar Syndrome. Vida VL (ed): Academic Press, 2017. 57-66. 10.1016/B978-0-12-8104064.00005-9

4. Dusenbery SM, Geva T, Seale A, Valente AM, Zhou J, Sena L, Geggel RL: Outcome predictors and implications for management of scimitar syndrome. Am Heart J. 2013, 165:770-777. 10.1016/j.ahj.2013.01.016

5. Al Rukban H, Al Ghaihab M, Tamimi O, Al-Saleh S: Clinical spectrum of infantile scimitar syndrome: a tertiary center experience. Ann Pediatr Cardiol. 2014, 7:29-33. 10.4103/0974-2069.126547

6. Gao Y-A, Burrows PE, Benson LN, Rabinovitch M, Freedom RM: Scimitar syndrome in infancy. J Am Coll Cardiol. 1993, 22:873-882. 10.1016/0735-1097(93)90206-G

7. Argueta-Morales IR, Meador LC, Nykanen DG, DeCampli WM: Infantile form of scimitar syndrome with contralateral pulmonary vein stenosis. Pediatr Cardiol. 2010, 31:550-552. 10.1007/s00246-009-9630-z

8. Onalan MA, Temur B, Aydin S, Erek E: Successful repair of infantile scimitar syndrome with contralateral pulmonary vein stenosis in an infant. Braz J Cardiovasc Surg. 2021, 36:133-136. 10.21470/1678-9741-20190228

9. Abman SH, Hansmann G, Archer SL, et al.: Pediatric pulmonary hypertension: guidelines from the American Heart Association and American Thoracic Society. Circulation. 2015, 132:2037-2099.

10.1161/CIR.0000000000000329 